\title{
Factorial Designs Application to Study Enhanced Bioremediation of Soil Artificially Contaminated with Weathered Bonny Light Crude Oil through Biostimulation and Bioaugmentation Strategy
}

\author{
Samuel E. Agarry ${ }^{*}$, Oladipupo O. Ogunleye \\ Biochemical Engineering and Biotechnology Research Laboratory, Department of Chemical Engineering, Ladoke Akintola Univer- \\ sity of Technology, Ogbomosho, Nigeria. \\ Email: "sam_agarry@yahoo.com, ooogunleye@yahoo.com
}

Received May $12^{\text {th }}, 2012$; revised June $9^{\text {th }}, 2012$; accepted July $11^{\text {th }}, 2012$

\begin{abstract}
The objective of this study was designed to evaluate the effects of biostimulation and bioaugmentation amendment agents (NPK fertilizer, Tween 80 and mixed culture) on the bioremediation of tropical soil samples artificially contaminated with Weathered Bonny Light Crude Oil (WBLCO). Response Surface Methodology (RSM) with Box Behnken Design (BBD) was used with three levels and three factors of NPK fertilizer (2 - $6 \mathrm{~g})$, Tween $80(5-15 \mathrm{mg} / \mathrm{l})$ and mixed culture $(0.5-1.5 \mathrm{~g} / \mathrm{l})$ as independent variables and WBLCO removal as dependent variable (response) in a six weeks remediation period. The results showed that the rate of WBLCO removal generally increased with increase in the amount of NPK fertilizer, Tween 80 and mixed culture (biomass), respectively. A statistically significant $(\mathrm{P}<$ 0.0001) second-order quadratic regression model for WBLCO removal (using design-expert statistical program (v. $6.0 .8)$ ) with a coefficient of determination, $\mathrm{R}(=0.9996)$ was obtained. Numerical optimization technique based on desirability function was carried out to optimize the bioremediation process. The optimum values for biostimulation and bioaugmentation amendment agents to achieve a predicted maximum WBLCO removal of 84.88 percent were found to be: NPK fertilizer, $4.25 \mathrm{~g}$; Tween $80,10.22 \mathrm{mg} / 1$ and mixed culture, $0.46 \mathrm{~g} / \mathrm{l}$. At this optimum point, the observed WBLCO removal was found to be 83.79 percent. The statistical analyses and the closeness of the experimental results and model predictions show the reliability of the regression model and thus, biostimulation and bioaugmentation of indigenous microbial density and activity can reduce remediation period of petroleum hydrocarbon contaminated environment and subsequently the cost of remediation.
\end{abstract}

Keywords: Bioremediation; Box-Behnken Designs; Crude Oil; Second-Order Quadratic Regression Model

\section{Introduction}

Crude oil is an extremely complex mixture of aliphatic and aromatic hydrocarbons, including volatile components of gasoline, petrol, kerosene, lubricating oil and solid asphaltene residues. In developed and developing countries, contamination of soil and marine environment by crude oil and petroleum products has become a serious problem. The main sources of this contamination can originate from natural oil seepage and human activities including extraction, transportation, utilization of petroleum (crude oil and natural gas), oil field installations, petroleum plants (refining), liquid fuel distribution and storage devices, transportation equipment for petroleum products, airports and illegal drillings in pipe lines [1-3].

"Corresponding author.
The scale of the hazards imposed on the natural environment depends on the surface of the area contaminated by petroleum products, their chemical composition, and the depth at which pollutants occur.

Crude oil causes a variety of risks when released into the environment. It is physically, chemically and biologically harmful to soil because of the presence of many toxic compounds, such as polycyclic aromatic hydrocarbons, benzene and its substituted and cycloalkane rings, in relatively high concentrations. The fate and effects of spilled crude oil and its products in soils have already been the subject of several studies [4-6]. Biodegradation of hydrocarbon compounds is one of the most important processes involved in the weathering and eventual removal of oil from the environment, particularly for its non-volatile components. Thus, potentially biodegrada- 
tion can be used for recovery of sensitive areas such as contaminated shorelines, marshes, and wetlands.

The term "enhanced bioremediation" encompasses a broad continuum of technologies that differ with respect to their inputs [7-9]. These technologies may involve the addition of electron acceptors or electron donors to stimulate naturally occurring microbial populations (biostimulation) or could be the introduction of specific microorganisms to enhance the biodegradation of the target compound (bioaugmentation). Bioremediation technologies have been developed for soils and coastal areas using the addition of nutrients and microbes [10-13]. However, it is known that biodegradation efficiencies of petroleum hydrocarbons in soil can be limited by physicochemical as well as biological factors, such as nutrients, $\mathrm{pH}$, temperature, moisture, oxygen, soil properties, and contaminant concentration, number and type or species of microorganisms [14-21]. Also, oil spills result in an imbalance in the carbon-nitrogen ratio at the spill site, because crude-oil is essentially a mixture of carbon and hydrogen. This causes a nitrogen deficiency in an oilsoaked soil, which retards the growth of bacteria and the utilization of carbon source(s). Huang et al. [22], Borresen and Rike [23], and Boopathy [24] determined optimum nutrient supplement levels at laboratory incubation experiments.

Application of surfactants to soil contaminated with petroleum hydrocarbons can potentially reduce the interfacial tension, increase its solubility and bioavailability, and thus facilitate their biodegradation [25,26]. Addition of synthetic surfactants to environments contaminated with petroleum hydrocarbons has been studied as a means by which their inhibitory effects on biodegradation were recognized, especially in concentrations above their critical micelle concentration (CMC) values [24, 27]. Currently, available information regarding the effects of biodegradable surfactants' addition such as Tween 80, Triton-X 100 and Brij 30 on enhanced biodegradation of petroleum hydrocarbons is limited [28-31]. Ongoing research and development seeking to improve methods by minimizing the number of experiments provide information about the direct additive effects of the study variables and interaction effects using design of experiment methods. Recently, this statistical technique has been successfully applied in many fields [22,32-34]. The statistical experiment designs most widely used in optimization experiments are termed response surface designs [22,32-37]. These designs provide information about direct effects, pair wise interaction effects and curvilinear variable effects. However, information on the optimization of biostimulation and/or bioaugmentation factors required for the enhanced bioremediation of petroleum hydrocarbons contaminated environment is still limited.

Therefore, the objective of this work is to study the bioremediation of soil artificially contaminated with "Weathered Bonny Light Crude Oil (WBLCO)" using the addition of NPK fertilizer (nutrient) and, Tween 80 (surfactant) as biostimulation factors and the addition of mixed culture (biomass) as bioaugmentation factor through Response Surface Methodology (RSM) via fullfactorial Box Behnken design in order to evaluate the influence of these biostimulation and/or bioaugmentation factors on the rate of WBLCO degradation and to optimize the factors for maximum crude oil removal.

\section{Materials and Methods}

\subsection{Soil Sample and Characterization}

An un-impacted soil samples from Ladoke Akintola University of Technology Agricultural Farms, Ogbomoso, were collected from the surface layer of the vadose zone $15-30 \mathrm{~cm}$ below land surface. The soil samples were air dried, homogenized, passed through a 2-mm (pore size) sieve and stored in a polythene bag at room temperature. Soil samples were characterized for their physicochemical and microbial parameters according to standard methods. Total organic carbon and total nitrogen of soil were determined using Walkley-Black and Macro-Kjeldahl methods respectively [38,39]. Soil $\mathrm{pH}$ was determined using $\mathrm{pH}$ meter fitted with a combined glass $\mathrm{pH}$ and reference electrode [38]. Soil moisture content was determined by evaporation on Whatman filter paper NO 1 (BDH Chemicals England) at $103^{\circ} \mathrm{C}$ to $105^{\circ} \mathrm{C}$ in an electrical oven. Available phosphorus was determined using Bray NO 1 Method [38,39]. The total hydrocarbon degrading bacteria (THDB) populations was determined by the vapor phase transfer method [40].

The determined soil parameters values are as follows: moisture content: $5.95 \pm 0.05$ (\%); total nitrogen: $0.25 \pm$ 0.04 (\%); available phosphorus: $0.12 \pm 0.02(\%)$; potassium: $0.31 \pm 0.05(\%)$; total organic carbon: $1.21 \pm 0.03$ $(\%)$; pH $5.9 \pm 0.2$, and total hydrocarbon-degrading bacteria (THDB): $3.7 \times 10^{5} \mathrm{cfu}^{-1}{ }^{-1}$. The hydrocarbon degrading bacterial types isolated from the soil samples were mainly Acinetobacter and Bacillus species. The soil characterization showed that the soil did not fulfill the nutrient (NPK) requirements for an efficient biodegradation process. Therefore, these elements were added in the form of NPK inorganic fertilizer $(20: 10: 10)$ to provide the proper nutrients required for the bioremediation process as well as bioaugment with Pseudomonas species (binary mixed culture of Pseudomonas aeruginosa and Pseudomonas fluorescence) that has been utilized as potential good degraders of petroleum hydrocarbons [41, 42]. 


\subsection{Chemicals and Microorganisms}

The Bonny light crude oil was obtained from Nigerian National Petroleum Corporation, Port-Harcourt, Nigeria. This study employed a biodegradable nonionic surfactant Tween 80 manufactured by Sigma-Aldrich, USA, which has an average molecular weight of 1310 and a critical micelle concentration (CMC) value of $15 \mathrm{mg} / \mathrm{l}$. NPK fertilizer (20:10:10) was purchased from an agrochemical store in Ogbomoso, Nigeria. Hexane solvent (BDH Chemicals, England) used for extraction of oil from soil were bought from a chemical store in Lagos, Nigeria.

Pseudomonas aeruginosa and Pseudomonas fluorescence were obtained from Department of Microbiology, Obafemi Awolowo University, Ile-Ife, Nigeria. Pure culture was maintained on nutrient agar slants at $4^{\circ} \mathrm{C}$. The strains were pre-grown in nutrient broth medium at room temperature $\left(28^{\circ} \mathrm{C} \pm 2^{\circ} \mathrm{C}\right)$ for $24 \mathrm{~h}$ and used for crude oil bioremediation studies. The overnight cultures were centrifuged, and the cell pellets was washed with physiological saline water thrice, re-suspended in saline water, homogenized and was used as stock solution. Different dilutions were made from the stock solution. A known volume of these solutions was filtered through $0.45 \mathrm{~m}$ filter paper (Millipore, USA) to find out the dry weight of cells. Corresponding absorbance was measured at 440 $\mathrm{nm}$ using a spectrophotometer. This information was used to prepare a calibration curve, dry weight versus absorbance. For unknown samples, the absorbance was measured at $440 \mathrm{~nm}$ and was converted to dry weight using absorbance versus dry weight calibration curve.

\subsection{Microcosms Preparation and Bioremediation Experimentation}

To optimize the range of experimentation for $2^{3}$ fullfactorial Box-Behnken design, the following experiments were performed in earthen pots (used as bioreactors) maintained at room temperature. Soil samples $(200 \mathrm{~g})$ were placed in earthen pots (microcosm) and were artificially contaminated with WBLCO to a level of $10 \% \mathrm{w} / \mathrm{w}$. The crude oil-contaminated soil in each earthen pot was amended with different amounts of NPK fertilizer (2 - 10 g), Tween $80(5-25 \mathrm{mg} / \mathrm{l})$ and binary mixed culture of $P$. aeruginosa and $P$. fluorescence $(0.2-1.0 \mathrm{~g} / \mathrm{l})$, respectively. Soil used as control was not amended with any nutrient or microorganisms. In total, 16 microcosms were settled and incubated for 42 days. All bioreactors were mixed manually once per week to enhance oxygenation, and kept moist during the 42 days experimental period. Samples were withdrawn at intervals of one week for residual Total Petroleum Hydrocarbon (TPH) analysis.

\subsection{Experimental Design and Data Analysis}

The Box-Behnken factorial experimental design em- ployed had three independent variables viz., NPK (20:10: 10) fertilizer, Tween 80 (surfactant) and biomass. Each of the independent amendment variables was studied at three levels of $-1,0,+1$ (Table 1), with 17 experimental runs. The levels were selected based on above preliminary study results. The variables optimized were NPK fertilizer in the range of $2-6 \mathrm{~g}$, Tween $80,5-15 \mathrm{mg} / \mathrm{l}$ and biomass, $0.2-0.6 \mathrm{~g} / \mathrm{l}$, respectively. Change in TPH (i.e. percent TPH reduction) was considered as experimental response. Efficiency of crude oil removal was assessed after 42 days. Table 2 shows the coded and actual values of factors and levels used in the experimental design. Crude oil-contaminated soil without biostimulation and bioaugmentation was also assayed as a control. The statistical software Design Expert 6.0.8, (Stat-Ease Inc., Minneapolis, USA) was used to evaluate the analysis of variance $(\mathrm{P}<0.05)$ to determine the significance of each term in the fitted equations and to estimate the goodness of fit in each case.

\subsection{Estimation of Total Petroleum Hydrocarbon}

Total Petroleum Hydrocarbon (TPH) was extracted from $10 \mathrm{~g}$ of soil with $50 \mathrm{ml}$ of hexane [43]. The extract was dried at room temperature by evaporation of the hexane solvent under a gentle nitrogen stream in a fume hood. After evaporation of the solvent, the amount of residual TPH was determined gravimetrically [43] by reading absorbance at $400 \mathrm{~nm}$ using visible range spectrophotometer (Model 6100 PYE UNICAM instruments England) and estimating the concentration from the standards curve, obtained from hexane extracts of fresh Bonny light crude oil at different concentrations.

\section{Results and Discussion}

\subsection{Natural Bioattenuation and Enhanced Bioremediation}

After performing 17 runs of the Box-Behnken Design (BBD) and one control, the results of the statistical experiment were analyzed with regard to the coded design matrix. The regression equation shows that the crude oil degradation rate was an experimental function of test variables in coded units. Table 3 shows that on the 42

Table 1. Experimental range and the levels of the variables.

\begin{tabular}{cccc}
\hline Dependent Variable & $\begin{array}{c}\text { Low Level } \\
(-1)\end{array}$ & $\begin{array}{c}\text { Medium } \\
\text { Level }(0)\end{array}$ & $\begin{array}{c}\text { High Level } \\
(+1)\end{array}$ \\
\hline NPK Fertilizer (A), g & 2.0 & 4.0 & 6.0 \\
Tween 80 (B), mg/1 & 5.0 & 10 & 15 \\
$\begin{array}{c}\text { Mixed Culture (Biomass) } \\
\text { (C), g/1 }\end{array}$ & 0.2 & 0.4 & 0.6 \\
\hline
\end{tabular}


Table 2. Coded and uncoded full-factorial Box-Behnken design for the three independent variables.

\begin{tabular}{|c|c|c|c|c|c|c|}
\hline \multirow{2}{*}{ Run } & \multicolumn{2}{|c|}{ NPK Fertilizer } & \multicolumn{2}{|c|}{ Tween 80} & \multicolumn{2}{|c|}{$\begin{array}{l}\text { Mixed Culture } \\
\text { (Biomass) }\end{array}$} \\
\hline & Code & $\begin{array}{l}\text { Value } \\
\text { (g) }\end{array}$ & Code & $\begin{array}{l}\text { Value } \\
(\mathrm{mg} / \mathrm{l})\end{array}$ & Code & $\begin{array}{l}\text { Value } \\
(\mathrm{g} / \mathrm{l})\end{array}$ \\
\hline 1 & -1 & 2 & -1 & 5 & 0 & 0.4 \\
\hline 2 & +1 & 6 & -1 & 5 & 0 & 0.4 \\
\hline 3 & -1 & 2 & +1 & 15 & 0 & 0.4 \\
\hline 4 & +1 & 6 & +1 & 15 & 0 & 0.4 \\
\hline 5 & -1 & 2 & 0 & 10 & -1 & 0.2 \\
\hline 6 & +1 & 6 & 0 & 10 & -1 & 0.2 \\
\hline 7 & -1 & 2 & 0 & 10 & +1 & 0.6 \\
\hline 8 & +1 & 6 & 0 & 10 & +1 & 0.6 \\
\hline 9 & 0 & 4 & -1 & 5 & -1 & 0.2 \\
\hline 10 & 0 & 4 & +1 & 15 & -1 & 0.2 \\
\hline 11 & 0 & 4 & -1 & 5 & +1 & 0.6 \\
\hline 12 & 0 & 4 & +1 & 15 & +1 & 0.6 \\
\hline 13 & 0 & 4 & - & 10 & - & 0.4 \\
\hline 14 & 0 & 4 & - & 10 & - & 0.4 \\
\hline 15 & 0 & 4 & - & 10 & - & 0.4 \\
\hline 16 & 0 & 4 & - & 10 & - & 0.4 \\
\hline 17 & 0 & 4 & 0 & 10 & 0 & 0.4 \\
\hline $\begin{array}{c}18 \\
\text { (Control) }\end{array}$ & - & - & - & - & - & - \\
\hline
\end{tabular}

day (6th week), crude oil content had decreased in all the earthen pot reactors. In control, natural biodegradation (natural bioattenuation) removed 44.78 percent of petroleum hydrocarbons. The reduction in petroleum hydrocarbon content of earthen pot reactors containing amendments was much higher (Table 3) in the same period.

These results indicate that the addition of biostimulant or biomass increased the rate of biodegradation. A considerable decrease in crude oil reduction was observed in runs 13 to 17, with a relatively high amount of NPK fertilizer, surfactant (Tween 80) and mixed culture (biomass); the residual oil reached $15.13-15.35$ percent of the initial crude oil concentration. The comparison of crude oil enhanced bioremediation and natural bioattenuation for each run is shown in Figure 1.

At $10 \%(\mathrm{w} / \mathrm{w})$ crude oil concentrations, run numbers 2 and 4 , and runs number 11 and 12 had same remediation condition with different concentration of Tween 80 (surfactant); results shows that addition of surfactant can
Table 3. Experimental design and results for light crude oil removal from contaminated soil.

\begin{tabular}{|c|c|c|}
\hline \multirow{2}{*}{$\begin{array}{l}\text { Experimental } \\
\text { Run }\end{array}$} & \multicolumn{2}{|c|}{ Percent Total Petroleum Hydrocarbon Reduction } \\
\hline & Observed Value & Predicted Value \\
\hline 1 & 75.85 & 75.80 \\
\hline 2 & 76.43 & 76.41 \\
\hline 3 & 74.96 & 74.98 \\
\hline 4 & 78.40 & 78.45 \\
\hline 5 & 79.00 & 79.11 \\
\hline 6 & 78.08 & 78.16 \\
\hline 7 & 77.04 & 76.96 \\
\hline 8 & 82.11 & 82.00 \\
\hline 9 & 79.54 & 79.47 \\
\hline 10 & 79.88 & 79.75 \\
\hline 11 & 79.85 & 79.98 \\
\hline 12 & 80.85 & 80.92 \\
\hline 13 & 84.65 & 84.72 \\
\hline 14 & 84.65 & 84.72 \\
\hline 15 & 84.87 & 84.72 \\
\hline 16 & 84.76 & 84.72 \\
\hline 17 & 84.69 & 84.72 \\
\hline 18 (Control) & 44.78 & - \\
\hline
\end{tabular}

enhance crude oil degradation. Similar observations have been reported for the use of non-ionic surfactant for the remediation of environment contaminated with petroleum hydrocarbons $[28,31,44]$. Effect of different concentrations of mixed culture (biomass) augmentation were investigated at the same condition of NPK and Tween 80 (run numbers 6 and 8, and run numbers 10 and 12) and the findings demonstrated that addition of mixed culture (biomass) can enhance the bioremediation process of soil contaminated with crude oil. This is in agreement with other workers observation [37,42]. Relatively run numbers 3 and 4; and run numbers 7 and 8 had same condition with different concentration of NPK; results shows that extra addition of NPK fertilizer (nutrient) extensively improved crude oil biodegradation from 75.66 to 78.43 percent and from 77.04 to 81.96 percent, respectively. A similar observation has been reported [45-48].

One of the major factors that limit hydrocarbon biodegradation is their low availability to microbial cells [37, 49]. In addition, efficiency of bioremediation is a function of the microbial viability in the natural environment 


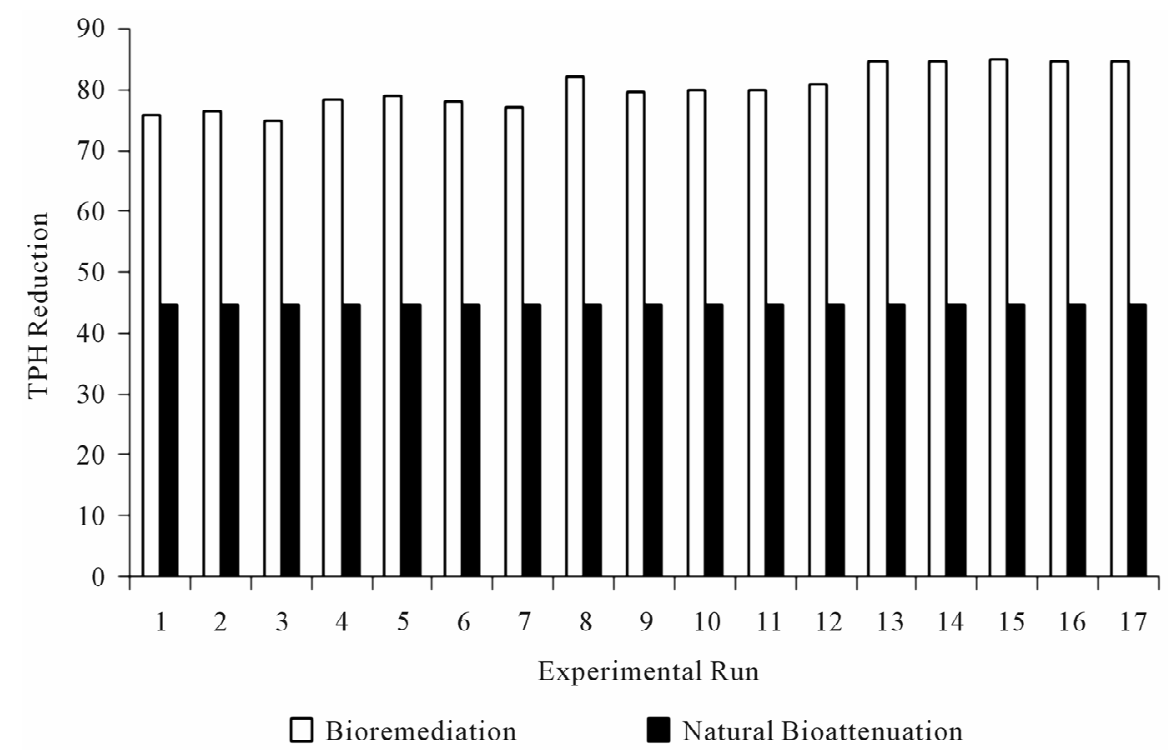

Figure 1. Comparison of percentage total petroleum hydrocarbon reduction due to enhanced bioremediation and natural bioattenuation.

[12]. Factors, such as nitrogen, phosphorus, and microorganism presence, have been reported to affect bioremediation; for example, limiting nitrogen is reported to enhance bioremediation [37,50,51]. Yuting et al. [52] and Mohajeri et al. [37] showed that natural attenuation removed 13 and $9-12.6$ percent of crude oil after 33 and 60 days incubation, respectively. When the soil was supplemented with nutrients (nitrogen and phosphorus) and biomass, 26.3 and 77 percent of the crude oil was respectively removed. The results suggest that high dose of nutrient amendment can accelerate the initial oil degradation rate and may shorten the period to clean up contaminated environments. The accelerating effect of amendment is stronger when nutrient availability is a limiting factor in the biodegradation of oil [37].

\subsection{Second Order Polynomial Regression Model and Statistical Analysis}

The experimental data were fitted to a second order polynomial regression model (Equation (1)) containing 3 linear, 3 quadratic and 3 interaction terms [53] using the same experimental design software to derive the equation for crude oil removal from contaminated soil.

$$
\begin{aligned}
Y= & \beta_{0}+\beta_{1} A+\beta_{2} B+\beta_{3} C+\beta_{11} A^{2}+\beta_{22} B^{2} \\
& +\beta_{33} C^{2}+\beta_{12} A B+\beta_{13} A C+\beta_{23} B C
\end{aligned}
$$

where $\beta_{0}$ is the value of the fixed response at the centre point of the design; $\beta_{1}, \beta_{2}, \beta_{3}$ are linear coefficients; $\beta_{11}, \beta_{22}, \beta_{33}$ are quadratic coefficients; $\beta_{12}, \beta_{13}, \beta_{23}$ are the interaction effect coefficients regression terms, respectively; $A, B$ and $C$ are the levels of independent amendment variables The significance of each coefficient in the equation was determined by F-test and P-values. F-test indicated that all the factors and interactions considered in the experimental design are statistically significant $(\mathrm{P}<0.05)$ at the 95 percent confidence level. The regression equation obtained after analysis of variance gives the level of total petroleum hydrocarbon reduction (crude oil removal) as a function of the different amendment variables: NPK, Tween 80, and mixed culture (biomass). All terms regardless of their significance are included in the following Equation (2):

$$
\begin{aligned}
Y= & 84.72+1.02 A+0.30 B+0.42 C-4.64 A^{2}-3.67 B^{2} \\
& -1.02 C^{2}+0.71 A B+1.50 A C+0.17 B C
\end{aligned}
$$

where $A$ is NPK concentration, $B$ is Tween concentration; $C$ is mixed culture concentration.

To test the fit of the model, the regression equation and determination coefficient $\left(\mathrm{R}^{2}\right)$ were evaluated (Table 4). The model F-value of 1176.12 implies the model is significant. There is only a 0.01 percent chance that a model F-value, this large could occur due to noise alone. The low probability value $(<0.0001)$ indicates that the model is significant. The value of the determination coefficient $\left(\mathrm{R}^{2}=0.9993\right)$ being a measure of goodness of fit to the model indicates a high degree of correlation between the observed value and predicted values. The determination coefficient $(\mathrm{R}=0.9996)$, suggests that more than 99.96 percent of the variance is attributable to the variables and indicated a high significance of the model. Thus, 0.04 percent of the total variance cannot be explained by the model. The fitted model is considered adequate if the F-test is significant $(\mathrm{P}<0.05)$. The analysis of variances 
Factorial Designs Application to Study Enhanced Bioremediation of Soil Artificially Contaminated with Weathered Bonny Light Crude Oil through Biostimulation and Bioaugmentation Strategy

Table 4. Analysis of variance for the quadratic response surface model fitting to the biodegradation data of WBLCO.

\begin{tabular}{cccccc}
\hline Source & $\begin{array}{c}\text { Sum of } \\
\text { Squares }\end{array}$ & DF & $\begin{array}{c}\text { Mean } \\
\text { Square }\end{array}$ & F-Value & P-Value \\
\hline Model & 186.44 & 9 & 20.72 & 1176.12 & $<0.0001$ \\
$\begin{array}{c}\text { Residual } \\
\text { (Error) }\end{array}$ & 0.120 & 7 & 0.018 & & \\
Lack of Fit & 0.089 & 3 & 0.030 & 3.40 & 0.1339 \\
$\begin{array}{c}\text { Pure Error } \\
\text { Correlation } \\
\text { Total }\end{array}$ & 0.035 & 4 & 0.009 & & \\
\hline
\end{tabular}

(ANOVA) quadratic regression model demonstrated that the model was highly significant, as was evident from the very low probability $(\mathrm{P}<0.0001)$ of the F-test and insignificant result from the Lack of Fit model $(\mathrm{P}=0.1339)$. The Lack of Fit test is performed by comparing the variability of the current model residuals to the variability between observations at replicate settings of the factors. The Lack of Fit F-value of 3.40 implies the Lack of Fit is not significant relative to the pure error. There is a 13.39 percent chance that a Lack of Fit F-value this large could occur due to noise.

The Lack of Fit is designed to determine whether the selected model is adequate to describe the observed data, or whether a more complicated model should be used. The Predicted R-Squared value of 0.9921 is in reasonable agreement with the Adjusted R-Squared value of 0.9985 . Adequate Precision measures the signal to noise ratio. A ratio $>4$ is desirable. The ratio of 95.765 obtained in this research indicates an adequate signal. This model can be used to navigate the design space. The coefficient of variation $(\mathrm{CV})$ as the ratio of the standard error of estimate to the mean value of the observed response is a measure of reproducibility of the model, generally a model can be considered reasonably reproducible if its $\mathrm{CV}$ is not greater than 10 percent. Hence, the low variation coefficient value ( $\mathrm{CV}=0.17$ percent) obtained indicates a high precision and reliability of the experiments.

The coefficient of the model (parameter estimation) and the corresponding P-values are presented in Table 5. The significance of regression coefficients was considered, ignoring those with an insignificant effect on the response at a significance level of 95 percent. The Pvalues of the regression coefficients suggest that among the test variables, linear, quadratic and interaction effects of NPK fertilizer, Tween 80 and mixed culture (biomass) are highly significant. The insignificant effects (factors and interactions) with $\mathrm{P}$-values higher than 0.05 , were ignored. In this study, $A, B, C, A^{2}, B^{2}, C^{2}, A B, A C$ and
Table 5. Coefficient of the model for light crude oil biodegradation.

\begin{tabular}{|c|c|c|c|c|c|}
\hline Variable & $\begin{array}{l}\text { Coefficient } \\
\text { Estimate }\end{array}$ & $\begin{array}{c}\text { Standard } \\
\text { Error }\end{array}$ & F-Value & P-Value & Remarks \\
\hline$\beta_{0}$ & 84.72 & 0.059 & 1176.12 & $<0.0001$ & Significant \\
\hline$\beta_{1}$ & 1.020 & 0.047 & 473.70 & $<0.0001$ & Significant \\
\hline$\beta_{2}$ & 0.300 & 0.047 & 41.56 & 0.0004 & Significant \\
\hline$\beta_{3}$ & 0.420 & 0.047 & 79.64 & $<0.0001$ & Significant \\
\hline$\beta_{11}$ & -4.640 & 0.065 & 5153.87 & $<0.0001$ & Significant \\
\hline$\beta_{22}$ & -3.670 & 0.065 & 3221.06 & $<0.0001$ & Significant \\
\hline$\beta_{33}$ & -1.020 & 0.065 & 250.30 & $<0.0001$ & Significant \\
\hline$\beta_{12}$ & 0.710 & 0.066 & 116.10 & $<0.0001$ & Significant \\
\hline$\beta_{13}$ & 1.500 & 0.066 & 509.27 & $<0.0001$ & Significant \\
\hline$\beta_{23}$ & 0.170 & 0.066 & 6.18 & 0.0418 & Significant \\
\hline
\end{tabular}

$B C$ are significant model terms.

Thus, statistical analysis of all the experimental data showed that NPK fertilizer, Tween 80 and mixed culture (biomass) concentration had a significant effect on TPH reduction (crude oil removal) during the study. Moreover, it is observed that NPK fertilizer (nutrients) exerted more pronounced linear effect (higher coefficient values) on crude oil removal (TPH reduction). That is, crude oil removal was mostly and positively influenced by NPK fertilizer (nutrients) followed by mixed culture (biomass) and Tween 80 (surfactant). The strong influence of nutrients on petroleum hydrocarbons removal has been clearly shown before in the previous works of Mohajeri et al. [37]. The quadratic effect of the independent amendment variables on the rate of crude oil removal was significant but negative.

Figure 2(a) shows the predicted versus actual plot of kerosene biodegradation. Actual values were determined for a particular run, and the predicted values were calculated from the approximating function used for the model. Figure 2(b) shows the studentized residuals and normal percent probability plot. Residual shows the difference between the observed value of a response measurement and the value that is fitted under the theorized model. Small residual values indicate that model prediction is accurate. The Cooks distance and studentized residuals illustrate the normal distribution and constant variance of the residuals, the goodness of fit, linearity of the fitted model, and the independence. Figure 2(c) shows Cook's distance plot; according to this plot there were no points that were potentially powerful due to their location in the factor. 


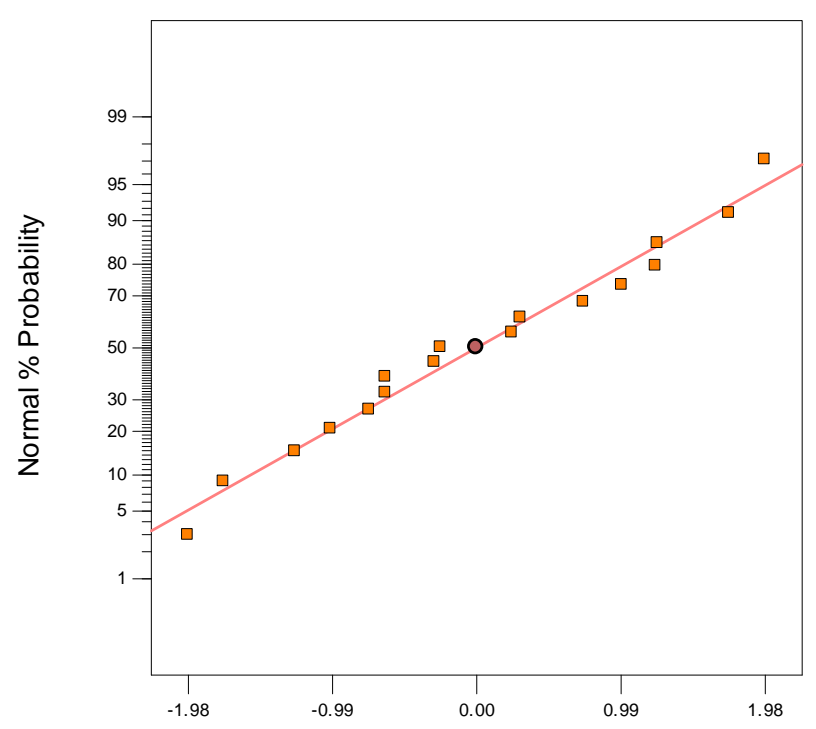

Studentized Residuals

(a)

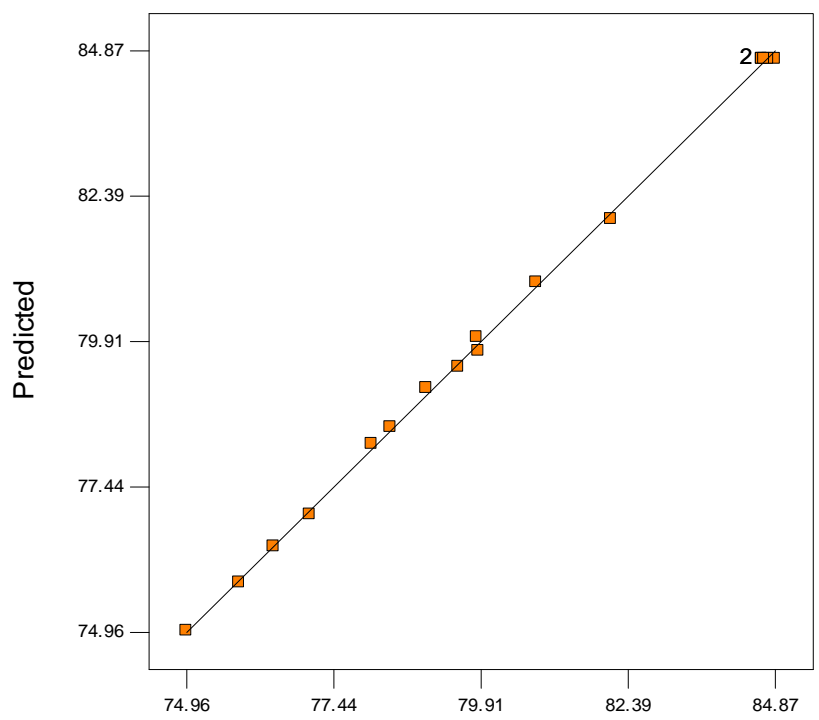

Actual

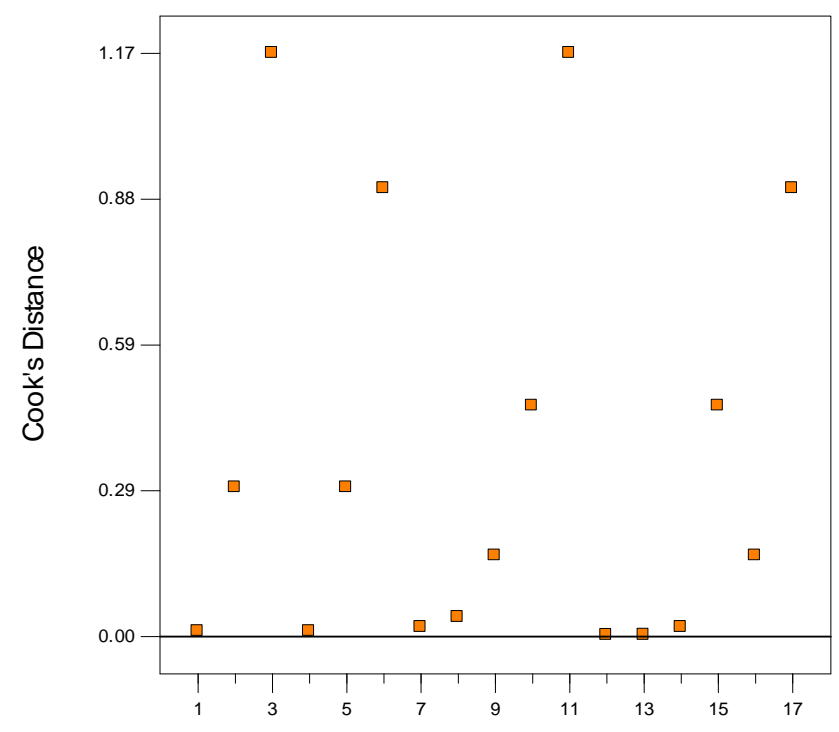

Run Number

(c)

Figure 2. (a) Normal plot of residuals plot of crude oil bioremediation; (b) Predicted versus actual plot of crude oil bioremediation; (c) Cook's distance plot of crude oil bioremediation.

\subsection{Influence of Variables Interaction on Weathered Light Crude Oil Removal}

Table 5 showed that WBLCO removal (i.e. TPH reduction) was influenced positively by interaction of NPK fertilizer (A) and Tween 80 (B); NPK fertilizer and mixed culture (biomass) (C); and Tween 80 (B) and mixed culture (C), respectively. The interaction effect of NPK fertilizer (nutrient) and mixed culture (biomass) exerted more pronounced positive influence (due to higher coefficient) on crude oil removal than the linear effect of NPK fertilizer and mixed culture. The graphical representation of the response shown in Figures 3(a)-(c) helped to visualize the effect of NPK fertilizer (A), Tween 80 (B) and mixed culture (C) on percent TPH reduction (crude oil removal). The effect of interaction of NPK fertilizer and Tween 80 on crude oil bioremediation is illustrated in Figure 3(a). The plot shows that higher 


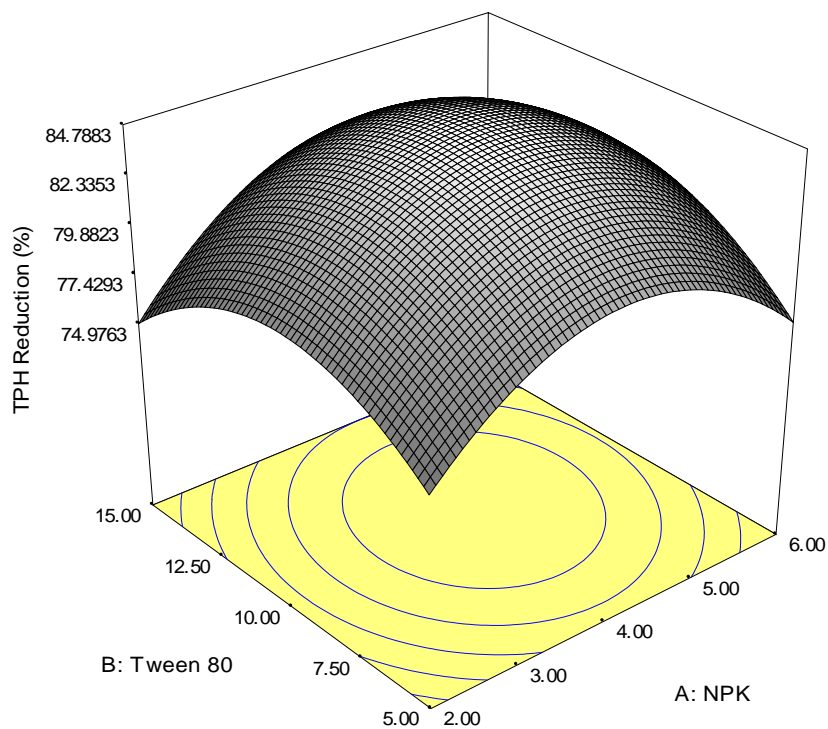

(a)

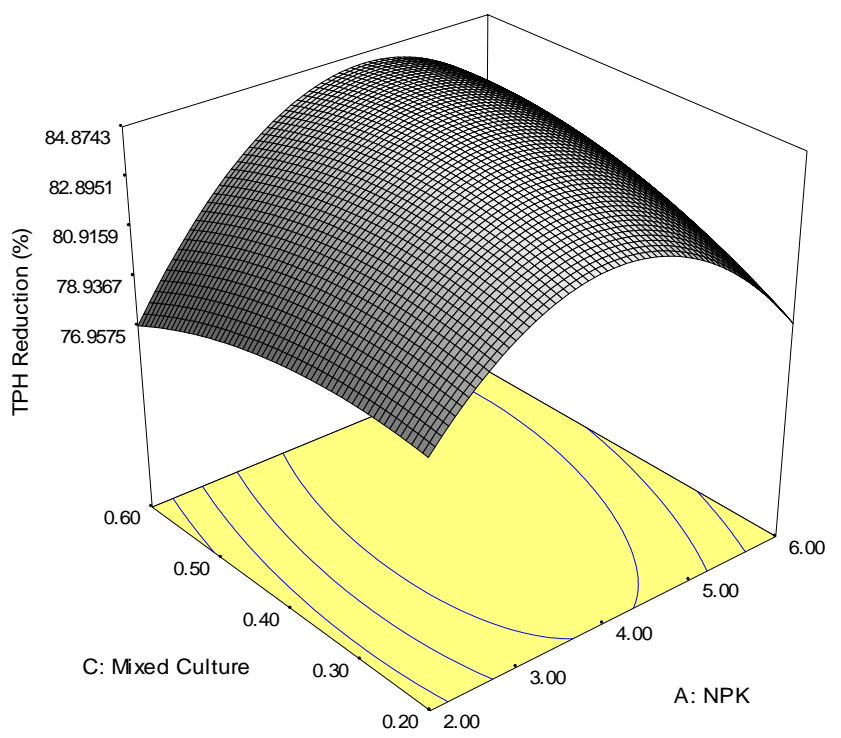

(b)

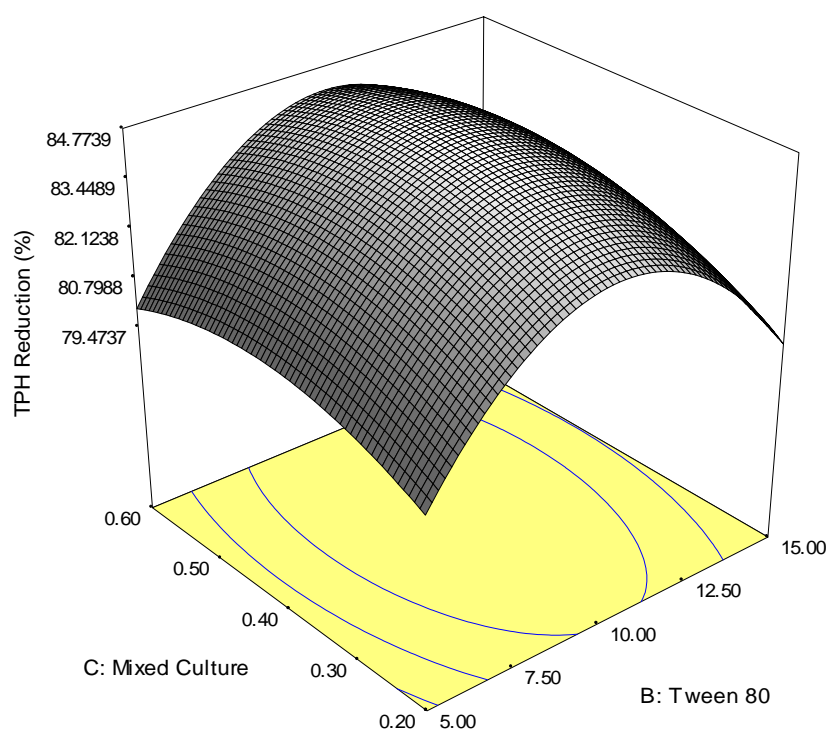

(c)

Figure 3. (a) Response surface 3D plots indicating interaction effects of NPK and Tween 80 variables; (b) Response surface 3D plots indicating interaction effects of NPK and mixed culture variables; (c) Response surface 3D plots indicating interaction effects of Tween 80 and mixed culture variables.

rate of TPH reduction was attained with increase in NPK fertilizer (nutrient) and Tween 80 (surfactant) concentrations. When $0.4 \mathrm{~g} / 1$ of mixed culture was used, the highest degradation yield of crude oil (84.79 percent) was obtained with $10 \mathrm{mg} / \mathrm{l}$ of Tween 80 surfactant and $4 \mathrm{~g} / \mathrm{l}$ of NPK fertilizer. This may be due to better bioavailability of substrate for the intrinsic microorganisms. However, availability of hydrocarbon-utilizing microorganism is a key issue in crude oil bioremediation [54].

Figure 3(b) shows the 3D response surface plot of the interaction effect between NPK fertilizer and mixed culture (biomass) concentrations. It is seen that a higher percent TPH reduction (crude oil removal) was obtained at a higher mixed culture (biomass) concentration and relatively high amount of NPK fertilizer. This three dimensional plot explains that both NPK fertilizer and mixed culture has individual impact on crude oil removal as the individual coefficient of both NPK fertilizer and mixed culture is positive and their interaction effect is positive. However, the impact of NPK fertilizer is more than mixed culture concentration as the individual coefficient value is higher for NPK fertilizer (1.02) than for mixed culture (0.42). The maximum bioremediation yield (84.97 percent) was achieved with around $0.4 \mathrm{~g} / \mathrm{l}$ of 
mixed culture and $4 \mathrm{~g}$ of NPK fertilizer. Nevertheless, this interaction demonstrates the best performance in the crude oil removal. Further increase in the amount of NPK fertilizer $(>4.0 \mathrm{~g})$, a significant decrease in bioremediation yields occurred. This suggests that at a fixed concentration of Tween 80, the amount of NPK fertilizer can be decreased and that of mixed culture concentration has to be increased for higher reduction in TPH yield. Nevertheless, excessive nutrients concentration may cause eutrophication and Harmful Algal Blooms (HABs) in the aquatic environment $[37,55,56]$.

Finally, Figure 3(c) shows the 3D response surface plot of the effect of interaction between Tween 80 (surfactant) and mixed culture (biomass) concentration. This plot demonstrates that both Tween 80 and mixed culture have positive mutual impact on the bioremediation process. At a fixed concentration of NPK fertilizer, it was observed that increase in Tween 80 and mixed culture (biomass) concentrations resulted in higher crude oil removal. The maximum reduction in TPH (84.77 percent) was obtained with $10 \mathrm{mg} / \mathrm{l}$ of Tween 80 and $4 \mathrm{~g}$ of NPK fertilizer.

\subsection{Factor Plot}

The factor effect function plot (Figure 4) was used to assess the effect of each factor graphically. From the trace plot as shown in Figure 4, it can be seen that each of the three variables used in the present study has its individual effect on crude oil removal by the intrinsic microbial populations in the soil. Gradual increase in NPK fertilizer, Tween 80 and mixed culture concentrations from low level (coded value -1 ) to a higher level (coded value +1 ) resulted in both increase and decrease of crude oil degradation (removal). Moreover, it is also to be noted from Figure 4 that over the range of $-1(2 \mathrm{~g})$ to $+1(6 \mathrm{~g})$ of NPK fertilizer, the crude oil degradation changed in a wide range. This was also the case for Tween 80; however, for mixed culture (biomass) it did not change over a wide range. This clearly indicates that keeping mixed culture (biomass) at the optimum level, a change in NPK fertilizer (nutrient) and Tween 80 (surfactant) will affect the bioremediation process more severely than done otherwise.

\subsection{Optimization and Validation}

Numerical optimization technique based on desirability function was carried out to determine the workable optimum conditions for the weathered light crude oil bioremediation process. In order to provide an ideal case for bioremediation, the goal for NPK fertilizer, Tween 80 and mixed culture (biomass) was set in range based upon the requirements of the oil bioremediation and crude oil removal was set on maximize. The predicted optimum (uncoded) values of NPK fertilizer, Tween 80 and mixed culture (biomass) were found to be $4.25 \mathrm{~g}, 10.22 \mathrm{mg} / \mathrm{l}$ and $0.46 \mathrm{~g} / 1$, respectively, to achieve 84.88 percent maximum crude oil (degradation) removal; while desirability was 1.00 for the experiment (Figure 5). Nevertheless, validation experiment was conducted to determine the optimum crude oil removal when the amendment variables were set at the favourable optimum levels established above, through BBD and RSM. Standard deviation and percent error were investigated for validation

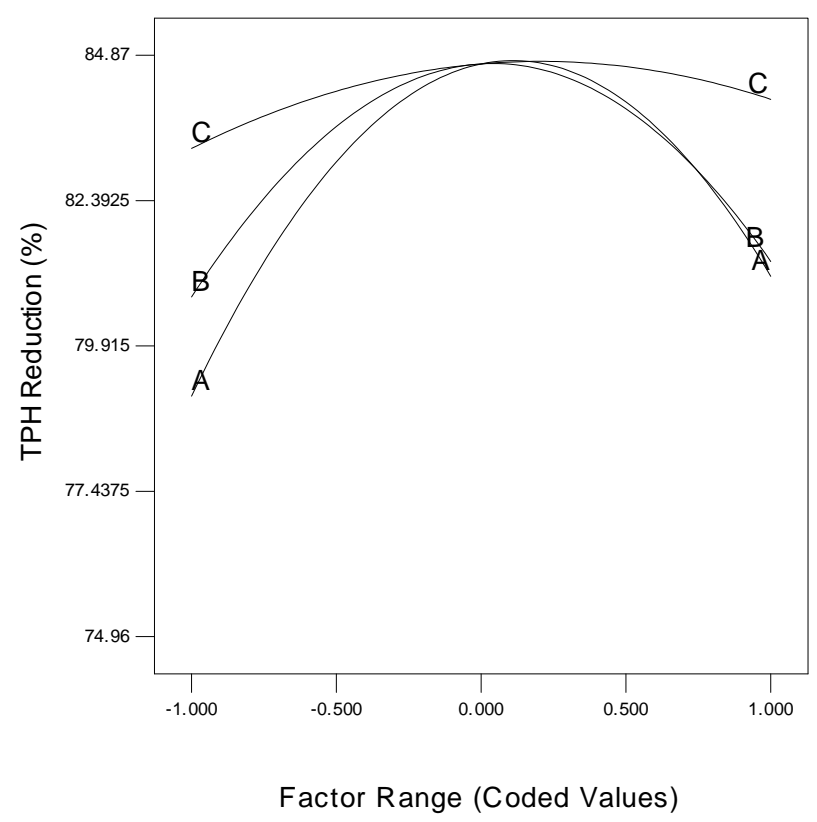

Figure 4. Factor plot representing the individual variable effect on crude oil bioremediation.

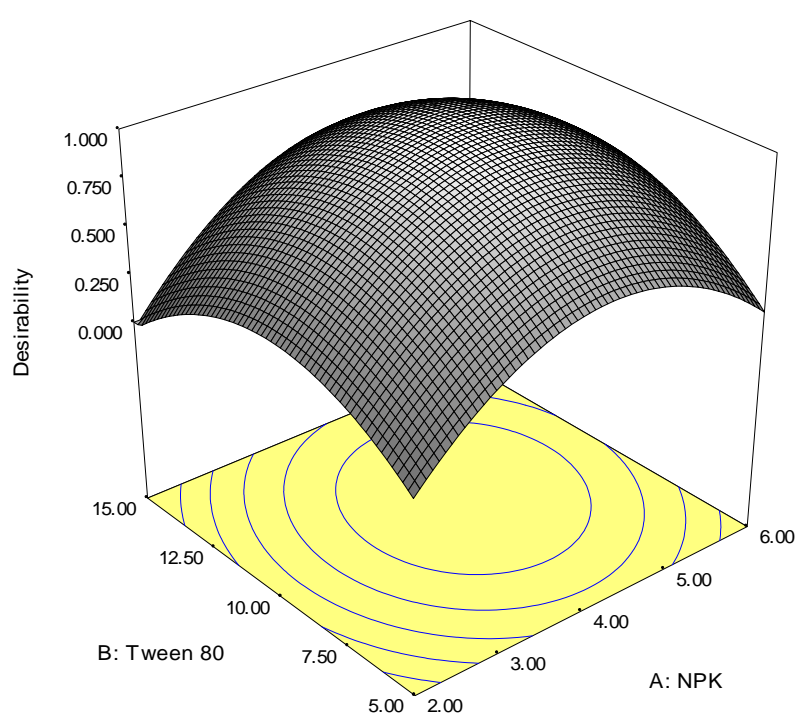

Figure 5. Desirability plot to optimize the light crude oil bioremediation process. 
of experiments. Errors between predicted and actual values were calculated according to Equation (3).

$$
\text { Error }=\frac{\text { Actual Value }- \text { Predicted Value }}{\text { Actual Value }} \times 100
$$

In the optimized condition for initial weathered light crude oil of $10 \%(\mathrm{w} / \mathrm{w})$ concentration, 83.79 percent crude oil removal was obtained. The percentage error between the predicted and actual values was found to be -1.3 . The results clearly indicated that no significant difference was observed. Marquez-Rocha et al. [57], Nievas et al. [58] and Thavasi et al. [59] have correspondingly reported up to 70,68 and 58 percent petroleum hydrocarbon removal from contaminated environment. A full factorial experimental design performed by Pala et al. [33] and Mohajeri et al. [37] to respectively assess the effects of three and four variables on the bioremediation of petroleum-contaminated soil showed that the hydrocarbon removal rate was around 80 percent.

\section{Conclusion}

The variations in crude oil degradation pattern with respect to nutrient (NPK fertilizer), surfactant (Tween 80) and mixed culture (biomass) contents were observed to be very significant. The results indicate that biostimulation and bioaugmentation of crude oil contaminated soil resulted in the enhancement of petroleum hydrocarbon degradation. RSM is a reliable and powerful tool for modeling and optimization of crude oil bioremediation processes; in the optimum conditions petroleum hydrocarbons were removed up to 83.79 percent in soil.

\section{REFERENCES}

[1] M. J. Kennish, "Practical Handbook of Marine Science," 3rd Edition, CRC Press Inc., Boca Raton, 2001.

[2] O. A. T. Ebuehi, I. B. Abibo, P. D. Shekwolo, K. I. Sigismund, A. Adoki, et al., "Remediation of Crude Oil Contaminated Soil by Enhanced Natural Attenuation Technique," Environmental Engineering, Vol. 9, No. 1, 2005, pp. 103-106.

[3] D. Wolicka, A. Suszek, A. Borkowski and A. Bielecka, "Application of Aerobic Microorganisms in Bioremediation In-Situ of Soil Contaminated by Petroleum Products," Bioresource Technology, Vol. 100, No. 13, 2009, pp. 3221-3227. doi:10.1016/j.biortech.2009.02.020

[4] Y. Murakami, S. Kitamura, K. Nakayama, S. Matsuoka and H. Sakaguchi, "Effects of Heavy Oil in the Developing Spotted Halibut, Verasper Variegates," Marine Pollution Bulletin, Vol. 57, No. 6-12, 2008, pp. 524-528. doi:10.1016/j.marpolbul.2008.02.043

[5] P. A. Kulakow and L. Erickson, "A Nationwide Feld Test of Petroleum Contaminated Soils," Proceedings of the 2000 Conference on Hazardous Waste Research, Denver, 23-25 May 2000, pp. 283-298.
[6] J. G. Leahy and R. R. Colwell, "Microbial Degradation of Hydrocarbons in the Environment," Microbiology Review, Vol. 54, No. 3, 1999, pp. 305-315.

[7] R. Margesin and F. Schinner, "Bioremediation (Natural Attenuation and Biostimulation) of Diesel-Oil-Contaminated Soil in an Alpine Glacier Skiing Area," Applied Environmental Microbiology, Vol. 67, No. 7, 2001, pp. 3127-3133. doi:10.1128/AEM.67.7.3127-3133.2001

[8] D. Sarkar, M. Ferguson, R. Datta and S. Birnbaum, "Bioremediation of Petroleum Hydrocarbons in Contaminated Soils: Comparison of Biosolids Addition, Carbon Supplementation, and Monitored Natural Attenuation," Environmental Pollution, Vol. 136, No. 1, 2005, pp. 187-195. doi:10.1016/j.envpol.2004.09.025

[9] H. Y. Chien, C. M. Kao, C. J. Jou, P. Y. Yang and C. C. Huang, "Application of Enhanced Bioremediation to Clean up Diesel-Oil Contaminated Soils: Laboratory Microcosm Study," Journal of Biotechnology, Vol. 136, 2008, p. S682. doi:10.1016/j.jbiotec.2008.07.1581

[10] Q. Lin and I. A. Mendelssohn, "Potential of Restoration and Phytoremediation with Juncus roemerianus for Diesel-Contaminated Coastal Wetlands," Ecology Engineering, Vol. 35, No. 1, 2009, pp. 85-91. doi:10.1016/j.ecoleng.2008.09.010

[11] H. Lei, M. Ting, L. Dan, L. Feng-Lai, L. Ru-Lin, et al., "Optimization of Nutrient Component for Diesel Oil Degradation by Rhodococcus erythropolis," Marine Pollution Bulletin, Vol. 56, No. 10, 2008, pp. 1714-1718. doi:10.1016/j.marpolbul.2008.07.007

[12] H. Joo, P. M. Ndegwa, M. Shoda and C. Phae, "Bioremediation of Oil-Contaminated Soil Using Candida catenulata and Food Waste," Environmental Pollution, Vol. 156, No. 3, 2008, pp. 891-896. doi:10.1016/j.envpol.2008.05.026

[13] P. F. Greenwood, S. Wibrow, S. J. George and M. Tibbett, "Sequential Hydrocarbon Biodegradation in a Soil from Arid Coastal Australia, Treated with Oil under Laboratory Controlled Conditions," Organic Geochemistry, Vol. 39, No. 9, 2008, pp. 1336-1346. doi:10.1016/j.orggeochem.2008.05.005

[14] L. Bradi, A. Mattei, S. Steffan and M. Marzona, "Hydrocarbon Degradation by a Soil Microbial Population with B-Cyclodeztrin as Surfactant to Enhance Bioavailability," Enzyme Microbial Technology, Vol. 27, 2000, pp. 709713.

[15] K. T. Semple, B. J. Reid and T. R. Fermor, "Impact of Composting Strategies on the Treatment of Soils Contaminated with Organic Pollutants," Environmental Pollution, Vol. 112, No. 2, 2001, pp. 269-283. doi:10.1016/S0269-7491(00)00099-3

[16] W. Namkoong, E. Y. Hwang, J. S. Park and J. Y. Choi, "Bioremediation of Diesel-Contaminated Soil with Composting," Environmental Pollution, Vol. 119, No. 1, 2002, pp. 23-31. doi:10.1016/S0269-7491(01)00328-1

[17] J. Sabate, M. Vinas and A. M. Solanas, "Laboratory Scale Bioremediation Experiments on Hydrocarbon-Contaminated Soils," International Biodeterioration \& Biodegradation, Vol. 54, No. 1, 2004, pp. 19-25. 


\section{doi:10.1016/j.ibiod.2003.12.002}

[18] F. M. Ghazali, R. N. Z. A. Rahman, A. B. Salleh and M. Basri, "Biodegradation of Hydrocarbons in Soil by Microbial Consortium," International Biodeterioration and Biodegradation, Vol. 54, No. 1, 2004, pp. 61-67. doi:10.1016/j.ibiod.2004.02.002

[19] M. Walter, K. S. H. Boyd-Wilson, D. McNaughton and G. Northcott, "Laboratory Trials on the Bioremediation of Aged Pentachlorophenol Residues," International Biodeterioration and Biodegradation, Vol. 55, No. 3, 2005, pp. 121-130. doi:10.1016/j.ibiod.2004.09.002

[20] R. M. Atlas and R. Bartha, "Fate and Effects of Polluting Petroleum in the Marine Environment," Residue Review, Vol. 49, No. 1, 2006, pp. 49-83.

[21] C. M. Kao, C. Y. Chen, S. C. Chen, H. Y. Chien and Y. L. Chen, "Application of In-Situ Biosparging to Remediate a Petroleum Hydrocarbon Spill Site: Field and Microbial Evaluation," Chemosphere, Vol. 70, No. 8, 2008, pp. 1492-1499. doi:10.1016/j.chemosphere.2007.08.029

[22] L. Huang, T. Mab, D. Li, F. Liang, R. Liu and G. Li, "Optimization of Nutrient Component for Diesel Oil Degradation by Rhodococcus erythropolis," Marine Pollution Bulletin, Vol. 56, No. 10, 2008, pp. 1714-1718. doi:10.1016/j.marpolbul.2008.07.007

[23] M. H. Borresen and A. G. Rike, "Effects of Nutrient Content, Moisture Content and Salinity on Mineralization of Hexadecane in an Arctic Soil Cold Region," Science Technology, Vol. 48, 2007, pp. 129-138.

[24] R. Boopathy, "Factors Limiting Bioremediation Technologies," Bioresource Technology, Vol. 74, No. 1, 2000, pp. 63-67. doi:10.1016/S0960-8524(99)00144-3

[25] C. N. Mulligan, R. N. Yong and B. F. Gibbs, "Surfactant Enhanced Remediation of Contaminated Soil: A Review," Engineering Geology, Vol. 60, No. 1-4, 2001, pp. 371-380. doi:10.1016/S0013-7952(00)00117-4

[26] A. Franzetti, P. Gennaro, G. Bestetti, M. Lasagni and D. Pitea, et al., "Bioremediation of Diesel-Contaminated Soils: Evaluation of Potential In-Situ Techniques by Study of Bacterial Degradation," Biodegradation, Vol. 12, No. 5, 2001, pp. 325-335. doi:10.1023/A:1014397732435

[27] L. G. Torres, N. Rojas, G. Bautista and R. Iturbe, "Effect of Temperature and Surfactant's HLB and Dose over the TPH-Diesel Biodegradation Process in Aged Soils," Process Biochemistry, Vol. 40, No. 10, 2005, pp. 3296-3302. doi:10.1016/j.procbio.2005.03.032

[28] T. T. Tsai, C. M. Kao, R. Y. Surampalli and H. Y. Chien, "Enhanced Bioremediation of Fuel-Oil Contaminated Soils: Laboratory Feasibility Study," Journal of Environmental Engineering, Vol. 135, No. 9, 2009, pp. 845-853. doi:10.1061/(ASCE)EE.1943-7870.0000049

[29] S. Wang and C. N. Mulligan, "An Evaluation of Surfactant Foam Technology in Remediation of Contaminated Soil," Chemosphere, Vol. 57, No. 9, 2004, pp. 1079-1089. doi:10.1016/j.chemosphere.2004.08.019

[30] H. Yu, L. Zhu and W. Zhou, "Enhanced Desorption and Biodegradation of Phenanthrene in Soil-Water Systems with the Presence of Anionic-Nonionic Mixed Surfac- tants," Journal of Hazardous Materials, Vol. 142, 2007, pp. 354-361. doi:10.1016/j.jhazmat.2006.08.028 P

[31] S. E. Agarry and C. N. Owabor, "Anaerobic Bioremediation of Marine Sediment Artificially Contaminated with Anthracene and Naphthalene," Environmental Technology, Vol. 32, No. 12, 2011, pp. 1375-1381. doi: $10.1080 / 09593330.2010 .536788$

[32] M. Ahmadi, F. Vahabzadeh, B. Bonakdarpour, E. Mofarrah and M. Mehranian, "Application of the Central Composite Design and Response Surface Methodology to the Advanced Treatment of Olive Oil Processing Wastewater Using Fenton's Peroxidation," Journal of Hazardous Materials, Vol. 123, No. 1-3, 2005, pp. 187-195. doi:10.1016/j.jhazmat.2005.03.042

[33] D. M. Pala, D. de Carvalho, J. Pinto and G. Sant'Anna Jr., "A Suitable Model to Describe Bioremediation of a Petroleum-Contaminated Soil," International Biodeterioration and Biodegradation, Vol. 58, No. 6, 2006, pp. $254-$ 260. doi:10.1016/j.ibiod.2006.06.026

[34] F. Rigas, K. Papadopoulou, V. Dritsa and D. Doulia, "Bioremediation of a Soil Contaminated by Lindane Utilizing the Fungus Ganoderma australe via Response Surface Methodology," Journal of Hazardous Materials, Vol. 140, No. 1-2, 2007, pp. 325-332. doi:10.1016/j.jhazmat.2006.09.035

[35] S. V. Mohan, B. P. Reddy and P. N. Sarma, "Ex Situ Slurry Phase Bioremediation of Chrysene Contaminated Soil with the Function of Metabolic Function: Process Evaluation by Data Enveloping Analysis (DEA) and Taguchi Design of Experimental Methodology (DOE)," Bioresource Technology, Vol. 100, No. 1, 2009, pp. 164172. doi:10.1016/j.biortech.2008.06.020

[36] A. C. Da Silva, F. J. S. de Oliveira, D. S. Bernardes and F. P. de Franca, "Bioremediation of Marine Sediments Impacted by Petroleum," Applied Biochemistry and Biotechnology, Vol. 153, No. 1-3, 2009, pp. 58-66. doi:10.1007/s12010-008-8457-Z

[37] L. Mohajeri, H. A. Aziz, M. H. Isa and M. A. Zahed, "A Statistical Experiment Design Approach for Optimizing Biodegradation of Weathered Crude Oil in Coastal Sediments," Bioresource Technology, Vol. 101, No. 3, 2010, pp. 893-900. doi:10.1016/j.biortech.2009.09.013

[38] C. A. Black, "Method of Soil Analysis II," American Society of Agronomy, Madison, 1965, pp. 573-590.

[39] APHA, "Standard Methods for the Examination of Water and Wastewater," American Public Health Association, Washington DC, 1985.

[40] S. C. Amanchukwu, A. Obafemi and G. C. Okpokwasili, "Hydrocarbon Degradation and Utilization by a Palm Wine Yeast Isolates," FEMS Microbiology Letters, Vol. 57, No. 2, 1989, pp. 151-154. doi:10.1111/j.1574-6968.1989.tb03290.x

[41] S. Barathi and N. Vasudevan, "Bioremediation of Crude Oil Contaminated Soil by Bioaugmentation of Pseudomonas fluorescens NS1," Journal of Environmental Science and Health Part A, Vol. A38, No. 9, 2003, pp. 1857 1866. doi:10.1081/ESE-120022884

[42] K. Das and A. K. Mukherjee, "Crude Petroleum-Oil Bio- 
degradation Efficiency of Bacillus subtilis and Pseudomonas aeruginosa Strains Isolated from a Petroleum-Oil Contaminated Soil from North-East India," Bioresource Technology, Vol. 98, No. 7, 2007, pp. 1339-1345. doi:10.1016/i.biortech.2006.05.032

[43] S. Mishra, J. Jyoti, R. C. Kuhad and B. Lal, "In Situ Bioremediation Potential of an Oily Sludge-Degrading Bacterial Consortium," Current Microbiology, Vol. 43, No. 5, 2001, pp. 328-335. doi:10.1007/s002840010311

[44] D. J. L. Prak and P. H. Pritchard, "Degradation of Polycyclic Aromatic Hydrocarbons Dissolved in Tween 80 Surfactant Solutions by Sphingomonas paucimobilis EPA 505," Canadian Journal of Microbiology, Vol. 48, No. 2, 2002, pp. 151-158. doi:10.1139/w02-004

[45] M. J. Ayotamuno, R. B. Kogbara, S. O. T. Ogaji and S. D. Probert, "Bioremediation of a Crude-Oil Polluted Agricultural-Soil at Port Harcourt, Nigeria," Applied Energy, Vol. 83, No. 11, 2006, pp. 1249-1257. doi:10.1016/j.apenergy.2006.01.003

[46] K. C. Ubochi, V. I. Ibekwe and E. U. Ezeji, "Effect of Inorganic Fertilizer on Microbial Utilization of Hydrocarbons in Oil Contaminated Soil," African Journal of Biotechnology, Vol. 5, No. 17, 2006, pp. 1584-1587.

[47] I. Sang-Hwan, I. Seokho, K. Dae Yaeon and K. Jeonggyu, "Degradation Characteristics of Waste Lubricants under Different Nutrient Condition," Journal of Hazard Materials, Vol. 143, No. 1-2, 2007, pp. 65-72. doi:10.1016/i.jhazmat.2006.08.059

[48] M. Chorom, H. S. Sharif and H. Mutamedi, "Bioremediation of a Crude Oil-Polluted Soil by Application of Fertilizers," Iran Journal of Environmental Health Science Engineering, Vol. 7, No. 4, 2010, pp. 319-326.

[49] C. Calvo, M. Manzanera, G. A. Silva-Castro, I. Uad and J. González-López, "Application of Bioemulsifiers in Soil Oil Bioremediation Processes, Future Prospects," Science Total Environment, Vol. 407, No. 12, 2009, pp. 36343640. doi:10.1016/j.scitotenv.2008.07.008

[50] L. O. Odokuma and A. A. Dickson, "Bioremediation of a Crude Oil Polluted Tropical Mangrove Environment," Journal of Applied Science and Environmental Management, Vol. 7, No. 2, 2003, pp. 23-29.

[51] L. Mohajeri, M. H. Isa, H. A. Aziz, M. A. Zahed and H. Nasrolahzadeh, "Survey of Petroleum Hydrocarbons
Bioremediation in Aquatic Environment," Proceedings of South East Asia Conference on the Advancement of Scientific and Social Research, Putra Palace, 14-15 December 2005.

[52] L. Yuting, Z. Xu, D. Dongjuan and L. Guanghe, "Porous Biocarrier-Enhanced Biodegradation of Crude Oil Contaminated Soil," International Biodeterioration \& Biodegradation, Vol. 63, No. 1, 2009, pp. 80-87. doi:10.1016/j.ibiod.2008.07.005

[53] D. C. Montgomery, "Design and Analysis of Experiments," 7th Edition, John Wiley, New York, 2008.

[54] X. Zhu, A. D. Venosa, M. T. Suidan and K. Lee, "Guidelines for the Bioremediation of Marine Shorelines and Freshwaters," US Environmental Protection Agency Office of Research and Development National Risk Management Research Laboratory Land Remediation and Pollution Control Division 26 W, Martin Luther King Drive Cincinnati, OH 45268, 2001.

[55] R. M. Atlas, "Petroleum Biodegradation and Oil Spill Bioremediation," Marine Pollution Bulletin, Vol. 31, No. 4-12, 1995, pp. 178-182. doi:10.1016/0025-326X(95)00113-2

[56] N. F. Y. Tam, Y. S. Wong and M. H. Wong, "Novel Technology in Pollutant Removal at Source and Bioremediation," Ocean Coastal Management, Vol. 52, No. 7, 2009, pp. 368-373. doi:10.1016/i.ocecoaman.2009.04.009

[57] F. J. Marquez-Rocha, J. Olmos-Soto, M. C. RosanoHernandez and M. Muriel-Garcia, "Determination of the Hydrocarbon-Degrading Metabolic Capabilities of Tropical Bacterial Isolates," International Biodeterioration \& Biodegradation, Vol. 55, No. 1, 2005, pp. 17-23. doi:10.1016/i.ibiod.2004.05.007

[58] M. L. Nievas, M. G. Commendatore, N. L. Olivera, J. L. Esteves and V. Bucalá, "Biodegradation of Bilge Waste from Patagonia with an Indigenous Microbial Community," Bioresource Technology, Vol. 97, No. 18, 2006, pp. 2280-2290. doi:10.1016/i.biortech.2005.10.042

[59] R. Thavasi, S. Jayalakshmi, T. Balasubramanian and I. M. Banat, "Biodegradation of Crude Oil by Nitrogen Fixing Marine Bacteria Azotobacter chroococcwn," Research Journal of Microbiology, Vol. 1, No. 1, 2006, pp. 401408. doi:10.3923/jm.2006.401.408 